Título artículo / Títol article:

A fair method for the calculation of the external costs of road traffic noise according to the Eurovignette Directive

Autores / Autors

Moliner Santisteve, Enrique ; Vidal Nadal, María Rosario ; Franco, Vicente

Revista:

Transportation Research Part D: Transport and Environment Volume 24, October 2013

Versión / Versió:

Preprint de l'autor

Cita bibliográfica / Cita bibliogràfica (ISO 690):
MOLINER, Enrique; VIDAL, Rosario; FRANCO, Vicente. A fair method for the calculation of the external costs of road traffic noise according to the Eurovignette Directive. Transportation Research Part D: Transport and Environment, 2013, 24: 52-61.

url Repositori UJI: http://hdl.handle.net/10234/88129 


\title{
A fair method for the calculation of the external costs of road traffic noise according to the Eurovignette Directive
}

\author{
Enrique Moliner*, Rosario Vidal, Vicente Franco \\ Engineering Design Group, Dept. of Mechanical Engineering and Construction, Universitat Jaume I, Av. Sos Baynat s/n, \\ 12071 Castellón, Spain \\ * Corresponding author. Tel.: +34 964729252. \\ E-mail address: kike.moliner@gmail.com (E. Moliner).
}

\section{Highlights}

- A new method is provided to calculate the external costs of road traffic noise.

- The method uses noise weighting factors for vehicle classes and times of the day.

- Improved weighting factors are developed for vehicle classes and times of the day.

- These factors can be regarded as suitable to be generalized to any road in Europe.

\begin{abstract}
The latest amendment of the Eurovignette Directive allows EU Member States to levy infrastructure charges (i.e. road tolls) in order to compensate for the external costs of noise caused by heavy goods vehicles (HGVs). To this end, it provides a method for the calculation of the external costs of road traffic noise. This method requires the use of different weighting factors according to the vehicle class and time of the day. However, the Eurovignette Directive does not provide specific values or guidelines to calculate these weighting factors. For this reason, weighting factors both for different vehicle classes and for different times of the day are developed in this paper. These factors are more reliable than those found in earlier studies, as they are highly differentiated to better account for the influence of key cost drivers, namely vehicle class, speed and time of the day. The method of the Eurovignette Directive focuses on the charging of HGVs for day and night. An alternative method is devised to extend the calculation of noise costs to other vehicle classes and time periods by applying the weighting factors developed herein.
\end{abstract}

Keywords: Road traffic noise; External costs; Eurovignette Directive; Weighting factors; Strategic noise maps

\section{Introduction}

The estimation and internalisation of external costs of transport has been an important issue in transport research and policy in Europe for many years. The European Commission addressed the matter of cost internalisation in several strategy papers (European Commission, 1995, 1998, 2001, 2006a, 2008, 2011), in which it stated that transport pricing should be based on marginal social cost (i.e. the social cost caused by an additional transport unit). Pricing instruments for the internalisation of external costs of transport have been implemented through EU Directives. The so-called Eurovignette Directive (European Commission, 1999) was initially adopted to allow EU Member States to charge heavy goods vehicles (HGVs) for the use of motorways to cover construction, maintenance and operation costs. It was later amended (European Commission, 2006b) to extend the charges to all roads in the trans-European road network and to allow a limited differentiation of charges according to the amount of congestion and certain environmental criteria. This first amendment also required to develop a reliable model for the assessment of all external costs to serve as the basis for future calculations of infrastructure charges. To this end, the European Commission commissioned the IMPACT project (Maibach et al., 2008), which provided an overview of the state of the art and best practice in the estimation of 
external costs of transport. Based on the findings of the IMPACT project, a new amendment of the Eurovignette Directive was recently adopted (European Union, 2011). This latest revision of the Eurovignette Directive allows EU Member States to charge HGVs for the costs of air pollution and noise, and provides methods for calculating both environmental costs. In the case of noise, the calculation method provides average costs per vehiclekilometre. These average noise costs are differentiated according to a set of key cost drivers, namely location, vehicle class and time of the day. The location of the roads is taken into account by distinguishing two types of road: suburban roads, which are subject to higher noise costs as they are located close to populated areas; and interurban roads, which are subject to lower noise costs as they are located in sparsely populated areas. The calculation method requires the use of weighting factors for different vehicle classes to account for differences in noise costs between different vehicle classes. The use of weighting factors for different times of the day is also required to distinguish between noise costs for day and night.

The latest revision of the Eurovignette Directive (European Union, 2011) shows some limitations. Most notably, it refers to the use of weighting factors for different vehicle classes and different times of the day in order to calculate differentiated noise costs by vehicle class and time of the day, but it does not provide specific values or guidelines to calculate these factors. Moreover, each EU Member State can only determine a single specific charge for each combination of vehicle class, type of road and time period. The method of the Eurovignette Directive applies a top-down approach to calculate the noise costs for two different types of road. This approach uses aggregated data from a large set of roads of the same type to compute the total noise costs, which are then divided by the total amount of traffic on these roads to obtain the average noise costs to be applied to all such roads. A bottom-up approach might be preferable to assess the noise costs of each particular road, or at least more detailed differentiation should be made between roads to take into account other key drivers influencing noise costs.

This paper provides differentiated and reliable weighting factors to calculate the external costs of road traffic noise in compliance with the Eurovignette Directive (European Union, 2011). The method of the Eurovignette Directive focuses on the charging of HGVs for day and night. An alternative method is devised to extend the calculation of noise costs to other vehicle classes and time periods by applying the weighting factors provided herein. A case study is presented in order to illustrate the application of the extended method. The average noise costs per vehicle-kilometre by vehicle class and time of the day are thus calculated for three different Spanish motorways.

\section{Material and methods}

The method for the calculation of the external costs of road traffic noise is presented below, as well as the inputs that serve as the basis for the calculations.

\subsection{External costs of road traffic noise and the Eurovignette Directive}

The Eurovignette Directive (European Union, 2011) provides a method to calculate the noise costs chargeable to HGVs according to the type of road (suburban and interurban) and time period (day and night). Under this method, noise costs are calculated by applying the following formulas:

$$
\begin{gathered}
N C V_{j, \text { daily }}=e \cdot \frac{\sum_{k} N C_{j k} \cdot P O P_{k}}{W A D T} \\
N C V_{j, \text { day }}=f_{\text {day }} \cdot N C V_{j, \text { daily }} \\
N C V_{j, \text { night }}=f_{\text {night }} \cdot N C V_{j, \text { daily }}
\end{gathered}
$$

where $N C V_{j}$ is the noise cost of one HGV on road type $j$ (in $€ /$ vehicle-km), $N C_{j k}$ is the noise cost per day per person exposed to noise level $k$ from road type $j$ (in $€ /$ person), $P O P_{k}$ is the population exposed to daily noise level $k$ per kilometre of road (in person/ $/ \mathrm{km}$ ), WADT is the weighted average daily traffic (in passenger car 
equivalent), $e$ is an equivalence factor between HGVs and passenger cars, and $f_{\text {day }}$ and $f_{\text {night }}$ are weighting factors for day and night periods.

The Eurovignette Directive (European Union, 2011) also provides the following maximum chargeable noise costs per vehicle-kilometre: $1.1 € c t$ for suburban roads during day, $2.0 €$ ct for suburban roads during night, 0.2 $€ c t$ for interurban roads during day, and $0.3 € c t$ for interurban roads during night. If the noise costs calculated from Eq. (1) to Eq. (3) exceed the maximum chargeable costs, the latter are used instead.

The method of the Eurovignette Directive (European Union, 2011) focuses on the charging of HGVs for day and night, but it is extended here to other vehicle classes and time periods by applying more differentiated weighting factors. A schematic representation of the extended method is shown in Fig. 1.

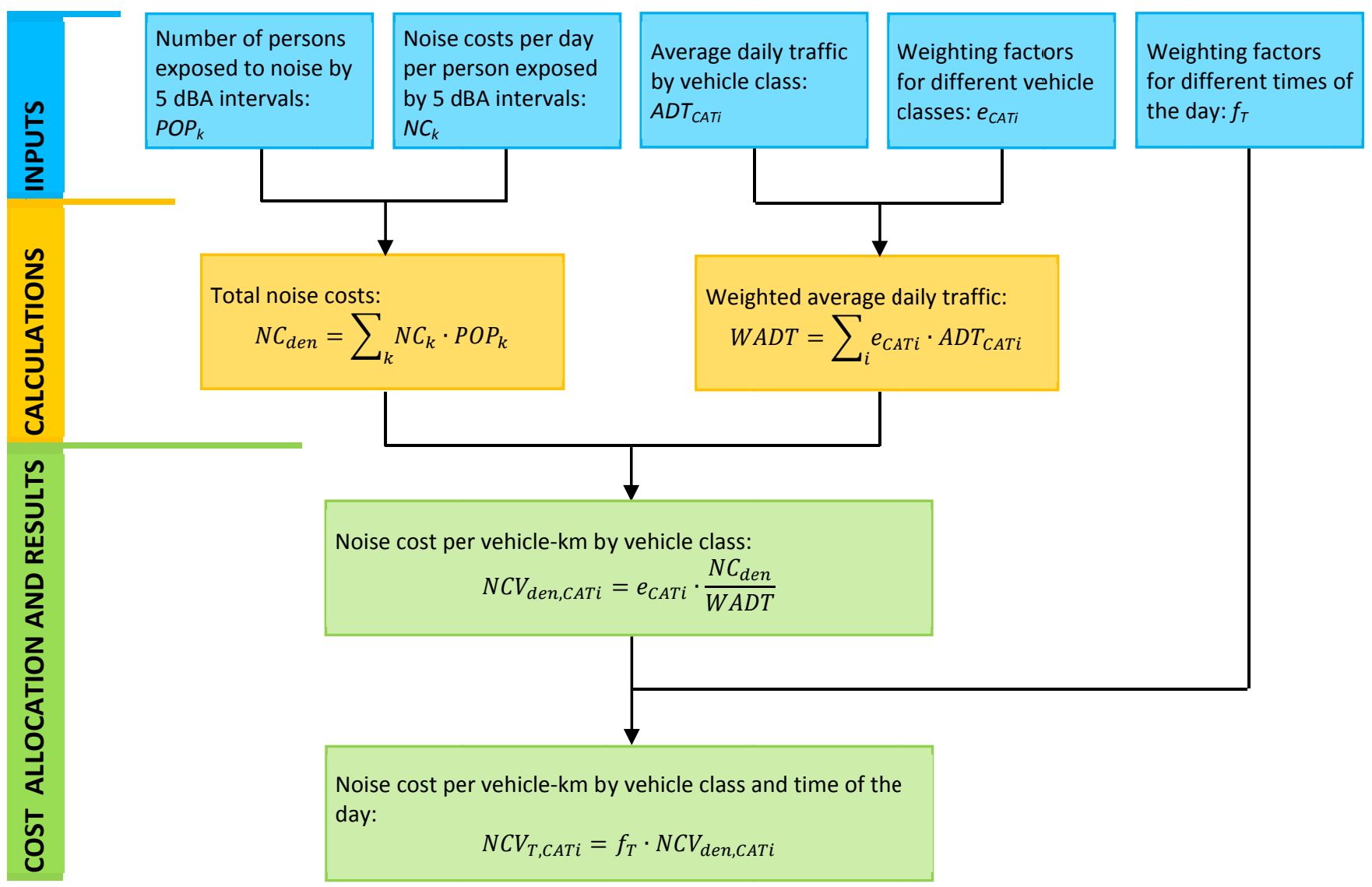

Fig. 1. Overview of the extended method: inputs, calculations, cost allocation and results.

\subsection{Traffic and noise exposure data and the Environmental Noise Directive}

Daily noise levels are measured by using the day-evening-night noise indicator $\left(L_{d e n}\right)$, which represents the Aweighted long-term average sound level determined over all 24-hour periods of a year. $L_{d e n}$ in A-weighted decibels (dBA) is defined in the so-called Environmental Noise Directive (European Commission, 2002) by the following formula:

$$
L_{\text {den }}=10 \cdot \log \left(\frac{12}{24} \cdot 10^{\frac{L_{\text {day }}}{10}}+\frac{4}{24} \cdot 10^{\frac{L_{\text {evening }}+5}{10}}+\frac{8}{24} \cdot 10^{\frac{L_{\text {night }}+10}{10}}\right)
$$

where $L_{\text {day }}, L_{\text {evening }}$ and $L_{\text {night }}$ are the A-weighted long-term average sound levels determined respectively over all the day $(12 \mathrm{~h})$, evening $(4 \mathrm{~h})$ and night $(8 \mathrm{~h})$ periods of a year. These noise levels are measured at the position of the receivers (normally at the most exposed façade of dwellings). The number of persons exposed to $L_{d e n}$ by 5 $\mathrm{dBA}$ intervals is multiplied by unit values for noise exposure costs (i.e. costs per person exposed) to calculate the 
total noise costs. Traffic data (volume, composition by vehicle class, and speed) are then required to allocate the total noise costs to individual vehicles of different classes.

All of the traffic and noise exposure data required by the calculation method are publicly available through strategic noise maps drafted under the Environmental Noise Directive (European Commission, 2002). EU Member States were required to make strategic noise maps for all their major roads (i.e. roads with more than three million vehicles per year) before 30 June 2012. The information from the strategic noise maps had to be submitted to the European Commission within six months of the above date. The data reported so far by EU Member States are available on the web-based public information systems Reportnet-EIONET ${ }^{1}$ and NOISE ${ }^{2}$.

\subsection{Noise costs per person exposed}

An extensive review of studies on the external costs of road traffic noise was performed within the IMPACT project (Maibach et al., 2008). Based on this review, the values from the HEATCO project (Bickel et al., 2006) for the noise costs per person exposed per dBA were recommended. These costs comprise the willingness to pay for reducing annoyance and the quantifiable costs of health effects. The HEATCO project provides country-specific values for the costs per year per person exposed for all countries of the EU-25 and Switzerland for the year 2002.

\subsection{Weighting factors for different vehicle classes}

The total noise costs are allocated to individual vehicles of different classes based on their corresponding shares in total noise emissions, estimated via traffic volumes by vehicle class. Since vehicles emit different noise levels depending on their class, weighting factors for different vehicle classes must be applied to correct for differences in noise emissions between classes. The Eurovignette Directive (European Union, 2011) refers to a weighting factor of no more than 4 between HGVs and passenger cars, but does not provide specific values or guidelines to calculate it. An internationally agreed set of weighting factors is lacking, and studies applying weighting factors have shown large differences among them (Maibach et al., 2008). The European Conference of Ministers of Transport (1998) used a weighting of 10:10:1 for the relative noise nuisance from HGVs, buses and cars, while the Organisation for Economic Cooperation and Development (OECD/INFRAS/Herry, 2003) used a weighting of 3:2.5:1. The IMPACT project (Maibach et al., 2008) recommends using the weighting factors for different road vehicle classes provided by CE Delft (van Essen et al., 2004). These are shown in Table 1.

Table 1

Weighting factors for different vehicle classes (Source: van Essen et al., 2004).

\begin{tabular}{lll}
\hline Vehicle class & Urban roads $(50 \mathrm{~km} / \mathrm{h})$ & Other roads $(80 \mathrm{~km} / \mathrm{h}$ or higher $)$ \\
\hline Passenger car petrol & 1.0 & 1.0 \\
Passenger car diesel & 1.2 & 1.0 \\
Passenger car LPG & 1.0 & 1.0 \\
Moped & 9.8 & 3.0 \\
Motorcycle & 13.2 & 4.2 \\
Bus & 9.8 & 3.3 \\
Van & 1.5 & 1.2 \\
HGV solo $<12$ tons GVW & 9.8 & 3.0 \\
HGV solo $>12$ tons GVW & 13.2 & 4.2 \\
HGV with trailer & 16.6 & 5.5 \\
\hline
\end{tabular}

The weighting factors in Table 1 show some limitations. These factors were calculated from noise reference values for light, medium heavy and heavy vehicles presented in the Dutch instruction for measuring and

\footnotetext{
${ }^{1}$ Reportnet-EIONET (European Environment Information and Observation Network): http://cdr.eionet.europa.eu

${ }^{2}$ NOISE (Noise Observation and Information Service for Europe): http://noise.eionet.europa.eu
} 
calculating road traffic noise (VROM, 2002). Factors for mopeds and motorcycles were based on expert assumptions. These factors are therefore specific for the Netherlands, while factors for the average European road vehicles would be preferable. Moreover, although different factors are provided for a wide range of vehicle classes, such factors are only differentiated according to two types of road: urban roads, where the speed is 50 $\mathrm{km} / \mathrm{h}$; and other roads, where the speed is $80 \mathrm{~km} / \mathrm{h}$ or higher. The ratio between the noise emission levels of different vehicle classes can vary significantly depending on the speed of each vehicle class, which may not be the same for all vehicle classes, even on the same road. Hence, more differentiated and accurate weighting factors that take into account various speeds would be more convenient. These should be based on noise emission values representative of the vehicle characteristics of the average European fleet.

\subsection{Weighting factors for different times of the day}

Nuisance due to noise exposure varies depending on the time of the day. To take this cost driver into account, the Eurovignette Directive (European Union, 2011) establishes the use of weighting factors for day and night periods. However, it does not provide specific values or guidelines to calculate these factors. Time of the day is only considered in a few studies estimating marginal noise costs for transport, such as the UNITE project (Bickel et al., 2003; Nash and partners, 2003) or studies by INFRAS/IWW (Schreyer et al., 2004) and by the Swiss Agency for the Environment, Forests and Landscape (Müller-Wenk and Hofstetter, 2003). Due to the logarithmic nature of the unit typically used for noise (i.e. the decibel), marginal noise costs are sensitive to existing traffic volumes; if the existing traffic volume is high, adding one extra vehicle will result in a small increase in the existing noise levels, and vice versa. Since studies that estimate marginal noise costs are based on specific case studies and marginal noise costs are highly dependent on the traffic situation, substantial differences have been found between the results of the different studies (Maibach et al., 2008). Consequently, the ratios between the marginal noise costs for different times of the day, which can be obtained from marginal cost studies based on specific traffic situations, are hardly transferable to other European roads. This justifies the need for developing weighting factors for different times of the day, which should be applicable to any road in Europe. These should preferably be differentiated according to three time periods, namely day, evening and night.

\section{Development of improved weighting factors}

This section deals with the theoretical development of weighting factors for the calculation of the external costs of road traffic noise. The approach for noise cost allocation used here as the basis for developing the weighting factors is first presented. The development of weighting factors both for different vehicle classes and for different times of the day is then explained and mathematical expressions for these factors are provided.

\subsection{Approach for noise cost allocation}

The total noise costs are calculated as a function of the population exposed to daily noise levels, which are measured by the noise indicator $L_{d e n}$ (see Eq. (4)). This indicator uses a weighted noise measure to take the impact of time of the day into account; evening noise carries a penalty of $5 \mathrm{dBA}$ and night noise carries a penalty of $10 \mathrm{dBA}$. These noise levels relate to sound pressure levels measured at the position of the receivers. Because noise exposure levels are directly caused by noise emissions from traffic, the total noise costs should be allocated to individual vehicles of different classes in each time period based on their shares in total noise emissions, but also considering the weighted noise measure mentioned above. To this end, a day-evening-night noise emission level $\left(L_{w, d e n}\right)$ is assumed here. $L_{W, \text { den }}$ can be defined by the same formula as $L_{\text {den }}$ but using sound power levels emitted by the traffic during each time period instead of sound pressure levels at the position of the receivers. The equivalent sound power level per unit length as emitted by a flow of vehicles of the same class $i$ during a time period $T\left(L_{W, T, C A T i}\right.$ in $\left.\mathrm{dBA} / \mathrm{m}\right)$ can be computed as follows (Kephalopoulos et al., 2012): 


$$
L_{W, T, C A T i}=L_{W, 0, C A T i}+10 \cdot \log \left(\frac{Q_{T, C A T i}}{1000 \cdot v_{T, C A T i}}\right)
$$

where $L_{W, O, C A T i}$ is the instantaneous sound power level emitted by a single vehicle of the class $i$ (in dBA), $Q_{T, C A T i}$ is the number of vehicles of the class $i$ passing per unit time during the time period $T$ (in veh/h), and $v_{T, C A T i}$ is the average speed of the vehicle flow of the class $i$ during the time period $T$ (in $\mathrm{km} / \mathrm{h}$ ). $L_{W, 0, C A T i}$ values can be calculated with a traffic noise emission model (e.g. CNOSSOS-EU (Kephalopoulos et al., 2012)) according to a set of input variables, like vehicle class, speed and so forth.

The equivalent sound power level caused by the total traffic during a time period $T\left(L_{W, T}\right.$, in $\left.\mathrm{dBA} / \mathrm{m}\right)$ can then be calculated through the logarithmic sum of the sound power levels associated with the flows of the different vehicle classes. The sum of equivalent sound power levels is computed as follows:

$$
L_{W, T}=10 \cdot \log \left(\sum_{i} 10^{\frac{L_{W, T, C A T i}}{10}}\right)
$$

The definition of the noise emission level $L_{W, d e n}$ together with the above formulas constitute the basis for noise cost allocation to individual vehicles of different classes in each time period. However, even though sound is usually measured in decibels, the sound power level is not the right measure to conduct noise cost allocation. Instead, the sound power level values must be translated from the logarithmic unit decibel into an energy unit that can be linearly disaggregated. The mathematical relationship between the sound power level in decibels and the sound power in watts is given by the following formula:

$$
L_{W}=10 \cdot \log \left(\frac{W}{W_{\text {ref }}}\right)
$$

where $L_{W}$ is the sound power level in decibels, $W$ is the sound power in watts produced by the source, and $W_{\text {ref }}$ is a reference sound power of $10^{-12}$ watts.

The sound power level $L_{W, \text { den }}$ can be converted to sound power through the relationship in Eq. (7). The dayevening-night sound power $\left(W_{d e n}\right.$, in $\left.W / m\right)$ is thus expressed as follows:

$$
W_{\text {den }}=\frac{12}{24} \cdot W_{\text {day }}+\frac{4}{24} \cdot 10^{\frac{5}{10}} \cdot W_{\text {evening }}+\frac{8}{24} \cdot 10^{\frac{10}{10}} \cdot W_{\text {night }}
$$

where $W_{\text {day }}, W_{\text {evening }}$ and $W_{\text {night }}$ are the sound power for the day, evening and night periods (in $W / m$ ). The sound power $W_{T}$ for each time period $T$ (day, evening and night) can be obtained by substituting Eq. (7) into Eq. (6) and Eq. (5), which results as follows:

$$
W_{T}=\sum_{i} W_{T, C A T i}=\sum_{i} W_{0, C A T i} \cdot \frac{Q_{T, C A T i}}{1000 \cdot v_{T, C A T i}}
$$

where $W_{T, C A T i}$ is the sound power per unit length emitted by a flow of vehicles of the class $i$ for the time period $T$ (in $\mathrm{W} / \mathrm{m}$ ) and $W_{0, \text { CATi }}$ is the instantaneous sound power emitted by a single vehicle of the class $i$ (in $W$ ).

At this point, noise cost allocation can be conducted on the basis of the shares of the individual vehicles of different classes for each time period in total noise emissions, which are expressed through the day-eveningnight sound power $W_{d e n}$. The total noise costs can first be allocated to the different time periods as follows:

$$
\begin{gathered}
N C_{\text {den }}=N C_{\text {day }}+N C_{\text {evening }}+N C_{\text {night }} \\
N C_{\text {day }}=\frac{\frac{12}{24} \cdot W_{\text {day }}}{W_{\text {den }}} \cdot N C_{\text {den }} \\
N C_{\text {evening }}=\frac{\frac{4}{24} \cdot 10^{\frac{5}{10}} \cdot W_{\text {evening }}}{W_{\text {den }}} \cdot N C_{\text {den }}
\end{gathered}
$$




$$
N C_{\text {night }}=\frac{\frac{8}{24} \cdot 10^{\frac{10}{10}} \cdot W_{\text {night }}}{W_{\text {den }}} \cdot N C_{\text {den }}
$$

where $N C_{\text {den, }} N C_{\text {day }}, N C_{\text {evening }}$ and $N C_{\text {night }}$ are the total noise costs per day and kilometre of road during the dayevening-night, day, evening and night periods, respectively.

The total noise costs for each time period can then be allocated to the flows of the different vehicle classes as follows:

$$
\begin{aligned}
& N C_{d a y, C A T i}=\frac{W_{d a y, C A T i}}{W_{d a y}} \cdot N C_{d a y}=\frac{\frac{12}{24} \cdot W_{d a y, C A T i}}{W_{d e n}} \cdot N C_{d e n} \\
& N C_{\text {evening,CATi }}=\frac{W_{\text {evening,CATi }}}{W_{\text {evening }}} \cdot N C_{\text {evening }}=\frac{\frac{4}{24} \cdot 10^{\frac{5}{10}} \cdot W_{\text {evening }, \text { CATi }}}{W_{\text {den }}} \cdot N C_{\text {den }} \\
& N C_{\text {night }, C A T i}=\frac{W_{\text {night,CATi }}}{W_{\text {night }}} \cdot N C_{\text {night }}=\frac{\frac{8}{24} \cdot 10^{\frac{10}{10}} \cdot W_{\text {night,CATi }}}{W_{\text {den }}} \cdot N C_{\text {den }}
\end{aligned}
$$

where $N C_{\text {day,CATi, }} N C_{\text {evening,CATi }}$ and $N C_{\text {night,CATi }}$ are the noise costs per day and kilometre of road for the vehicle flow of the class $i$ during the day, evening and night periods, respectively.

Finally, the average noise costs per vehicle-kilometre by vehicle class and time of the day can be expressed as a function of the total noise costs as follows:

$$
\begin{gathered}
N C V_{\text {day }, \text { CATi }}=\frac{N C_{\text {day }, \text { CATi }}}{12 \cdot Q_{\text {day }, \text { CATi }}}=\frac{\frac{1}{24} \cdot W_{\text {day }, \text { CATi }}}{Q_{\text {day }, C A T i} \cdot W_{\text {den }}} \cdot N C_{\text {den }} \\
N C V_{\text {evening }, C A T i}=\frac{N C_{\text {evening }, C A T i}}{4 \cdot Q_{\text {evening }, C A T i}}=\frac{\frac{1}{24} \cdot 10 \frac{5}{10} \cdot W_{\text {evening }, C A T i}}{Q_{\text {evening }, C A T i} \cdot W_{\text {den }}} \cdot N C_{\text {den }} \\
N C V_{\text {night }, C A T i}=\frac{N C_{\text {night }, C A T i}}{8 \cdot Q_{\text {night }, C A T i}}=\frac{\frac{1}{24} \cdot 10^{\frac{10}{10}} \cdot W_{\text {night }, C A T i}}{Q_{\text {night }, C A T i} \cdot W_{\text {den }}} \cdot N C_{\text {den }}
\end{gathered}
$$

where $N C V_{\text {day, } C A T i}, N C V_{\text {evening,CATi }}$ and $N C V_{\text {night,CATi }}$ are the average noise costs per vehicle-kilometre for a vehicle of the class $i$ during the day, evening and night periods, respectively.

\subsection{Weighting factors for different vehicle classes}

Traffic volumes by vehicle class can be used to allocate the total noise costs to individual vehicles of different classes. Weighting factors for different vehicle classes must be applied to the corresponding traffic volumes to correct for differences in noise emissions between vehicle classes. Each weighting factor describes the relationship between the costs per vehicle-kilometre for a given vehicle class and the costs per vehicle-kilometre for a vehicle class taken as a reference (usually passenger car). Based on this relationship and using the equations presented in Section 3.1, the weighting factor for a vehicle class $i$ and a time period $T\left(e_{T, \text { CATi }}\right)$ can be expressed as follows:

$$
e_{T, C A T i}=\frac{N C V_{T, C A T i}}{N C V_{T, C A T r e f}}=\frac{W_{T, C A T i} \cdot Q_{T, C A T r e f}}{W_{T, C A T r e f} \cdot Q_{T, C A T i}}=\frac{W_{0, C A T i} \cdot v_{T, C A T r e f}}{W_{0, \text { CATref }} \cdot v_{T, C A T i}}
$$

Hence, it can be observed that weighting factors for different vehicle classes depend only on the instantaneous sound power emitted by single vehicles of the different classes and the average speed of these vehicles. The instantaneous sound power does not depend on the time of the day and the average speed can be 
assumed to be the same for all time periods; only a few cases have been found in strategic noise maps ${ }^{3}$ where the speed for the night period is slightly higher (about $5 \mathrm{~km} / \mathrm{h}$ ) than for other time periods. As a result, the weighting factors can be considered independent of the time of the day, as expressed below:

$$
e_{C A T i}=\frac{N C V_{T, C A T i}}{N C V_{T, C A T r e f}}=\frac{W_{0, C A T i} \cdot v_{C A T r e f}}{W_{0, \text { CATref }} \cdot v_{C A T i}}
$$

$W_{0}$ values can be calculated with a suitable traffic noise emission model according to a set of input variables, like vehicle class, speed and so forth. The noise emission model from the CNOSSOS-EU project (Kephalopoulos et al., 2012) has been used herein. This model provides the instantaneous sound power level of an average European road vehicle under a set of reference conditions as a function of speed for different vehicle classes: light motor vehicles (CAT1), medium heavy vehicles (CAT2), heavy vehicles (CAT3), mopeds (CAT4a), and motorcycles (CAT4b). The instantaneous sound power values derived from the CNOSSOS-EU model have been inserted in Eq. (21) to calculate a set of weighting factors for different vehicle classes according to the speeds of the vehicles. These factors have been calculated for multiple combinations of vehicle speeds ranging from 50 to $130 \mathrm{~km} / \mathrm{h}$ in intervals of $10 \mathrm{~km} / \mathrm{h}$ and assuming that the speeds of the different vehicle classes differ by no more than $50 \mathrm{~km} / \mathrm{h}$ from the speed of the reference vehicle class. The weighting factors thus obtained for the different vehicle classes are shown as points in Fig. 2. The weighting factors for CAT1 (which includes passenger cars, vans $\leq 3.5$ tons, sport utility vehicles, and multi-purpose vehicles including trailers and caravans) are always 1 because CAT1 is taken as the reference vehicle class.

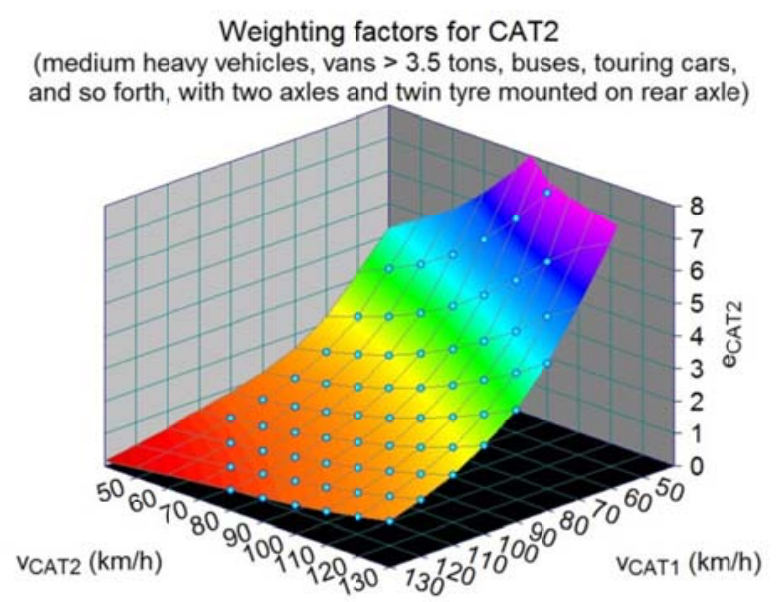

Weighting factors for CAT4a (mopeds, tricycles or quads with $50 \mathrm{cc}$ )

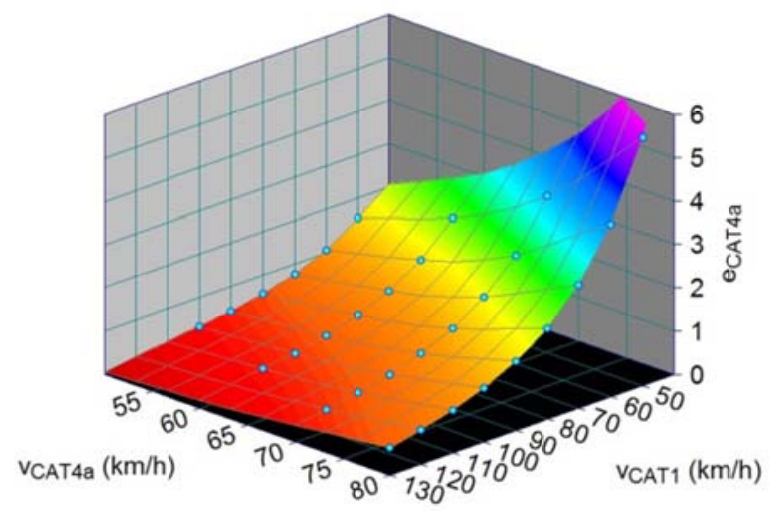

Weighting factors for CAT3

(HGVs, touring cars, buses, with three or more axles)

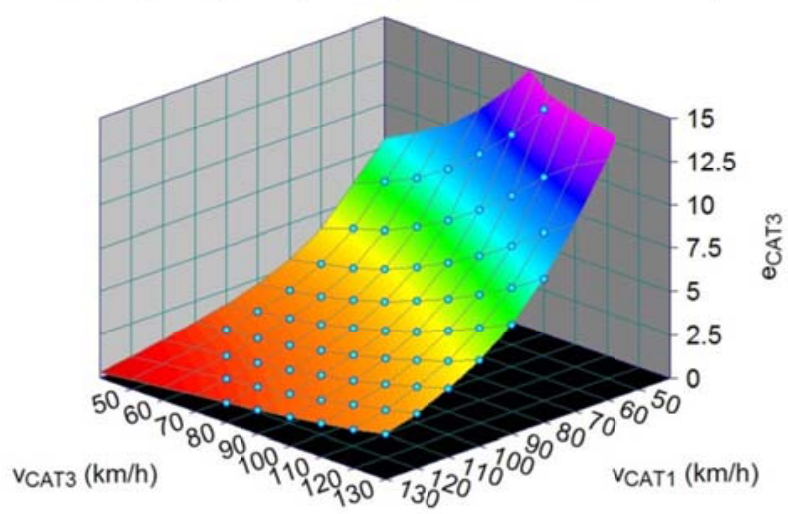

Weighting factors for CAT4b (motorcycles, tricycles or quads $>50 \mathrm{cc}$ )

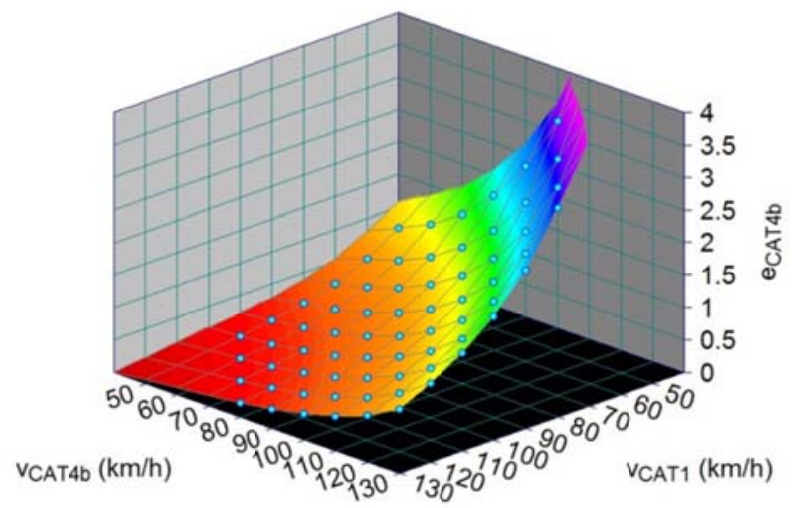

Fig. 2. Weighting factors for different vehicle classes according to the speeds of the vehicles.

\footnotetext{
${ }^{3}$ The strategic noise maps for Spanish major roads have been consulted through the Spanish Information System on Noise Pollution: http://sicaweb.cedex.es
} 
The surface fitting software TableCurve $3 \mathrm{D}^{\circledR}$ has been used to convert the series of data points shown in Fig. 2 for each vehicle class into simplified surface equations. The weighting factors for each vehicle class can be defined by rational functions with the following form:

$$
e_{C A T i}=\frac{p_{0,0}+p_{0,1} \cdot v_{C A T i}+p_{1,0} \cdot v_{C A T r e f}+p_{1,1} \cdot v_{C A T i} \cdot v_{C A T r e f}+p_{0,2} \cdot v_{C A T i}^{2}+p_{2,0} \cdot v_{C A T r e f}^{2}}{1+q_{0,1} \cdot v_{C A T i}+q_{1,0} \cdot v_{C A T r e f}+q_{1,1} \cdot v_{C A T i} \cdot v_{C A T r e f}+q_{0,2} \cdot v_{C A T i}^{2}+q_{2,0} \cdot v_{C A T r e f}^{2}}
$$

The coefficients of Eq. (22) have been computed for each vehicle class using the surface fitting software. The coefficient of determination $\left(r^{2}\right)$ and the standard error $(S E)$ of the equations for each vehicle class have also been computed. The equation coefficients and the fit statistics are shown in Table 2.

Table 2

Coefficients and fit statistics of Eq. (22) for different vehicle classes.

\begin{tabular}{lllll}
\hline Coefficient & CAT2 & CAT3 & CAT4a & CAT4b \\
\hline$p_{0,0}$ & $1.088 \mathrm{E}+01$ & $9.247 \mathrm{E}+00$ & $2.819 \mathrm{E}+00$ & $1.571 \mathrm{E}+00$ \\
$p_{0,1}$ & $-5.349 \mathrm{E}-02$ & $-1.107 \mathrm{E}-01$ & $-3.888 \mathrm{E}-03$ & $-9.645 \mathrm{E}-03$ \\
$p_{1,0}$ & $-1.161 \mathrm{E}-02$ & $7.633 \mathrm{E}-02$ & $-3.127 \mathrm{E}-02$ & $-1.459 \mathrm{E}-02$ \\
$p_{1,1}$ & $-3.686 \mathrm{E}-04$ & $-8.047 \mathrm{E}-04$ & $-2.035 \mathrm{E}-05$ & $1.444 \mathrm{E}-04$ \\
$p_{0,2}$ & $1.918 \mathrm{E}-03$ & $3.457 \mathrm{E}-03$ & $2.639 \mathrm{E}-04$ & $-2.750 \mathrm{E}-05$ \\
$p_{2,0}$ & $2.135 \mathrm{E}-05$ & $-2.091 \mathrm{E}-04$ & $1.033 \mathrm{E}-04$ & $1.082 \mathrm{E}-05$ \\
$q_{0,1}$ & $5.674 \mathrm{E}-03$ & $1.077 \mathrm{E}-02$ & $-3.718 \mathrm{E}-02$ & $-2.245 \mathrm{E}-02$ \\
$q_{1,0}$ & $-2.580 \mathrm{E}-02$ & $-5.621 \mathrm{E}-02$ & $4.984 \mathrm{E}-02$ & $1.479 \mathrm{E}-02$ \\
$q_{1,1}$ & $-2.150 \mathrm{E}-04$ & $7.427 \mathrm{E}-05$ & $-5.864 \mathrm{E}-04$ & $-2.540 \mathrm{E}-04$ \\
$q_{0,2}$ & $-2.886 \mathrm{E}-06$ & $-6.369 \mathrm{E}-05$ & $3.164 \mathrm{E}-04$ & $1.548 \mathrm{E}-04$ \\
$q_{2,0}$ & $1.504 \mathrm{E}-03$ & $1.312 \mathrm{E}-03$ & $1.222 \mathrm{E}-04$ & $1.319 \mathrm{E}-04$ \\
$r^{2}$ & $1.000 \mathrm{E}+00$ & $1.000 \mathrm{E}+00$ & $1.000 \mathrm{E}+00$ & $9.980 \mathrm{E}-01$ \\
$S E$ & $5.225 \mathrm{E}-03$ & $1.194 \mathrm{E}-02$ & $6.796 \mathrm{E}-03$ & $4.075 \mathrm{E}-02$ \\
\hline
\end{tabular}

The above weighting factors and their mathematical expressions have been calculated under a set of reference conditions: (1) constant vehicle speed; (2) a flat road; (3) an air temperature of $20^{\circ} \mathrm{C}$; (4) a virtual reference road surface, consisting of an average of dense asphalt concrete $0 / 11$ and stone mastic asphalt $0 / 11$, between 2 and 7 years old and in a representative maintenance condition; (5) a dry road surface; (6) a vehicle fleet for which the characteristics correspond to the values found for the European average (Peeters and van Blokland, 2007); and (7) no studded tyres. The CNOSSOS-EU model (Kephalopoulos et al., 2012) includes several correction factors to account for variations in noise emissions due to regional variations in vehicle fleet characteristics, meteorological conditions, road properties or driving behaviour. The effects of regional variations have also been investigated by performing a sensitivity analysis of regional parameters to estimate their influence on the weighting factors. The results of the sensitivity analysis are shown in Table 3.

It should be noted that regional variations are considered a second-order effect. The acceleration and deceleration of vehicles may have a significant effect, but it is restricted to the vicinity of crossings with traffic lights and roundabouts. Moreover, the uncertainty in the estimation of acceleration and deceleration of the traffic can be higher than the effect on noise emissions. Most of the attention was therefore focused on developing weighting factors that account for the vehicle classes and speeds in European roads under the reference conditions. 
Table 3

Sensitivity analysis of regional parameters influencing weighting factors.

\begin{tabular}{|c|c|c|c|}
\hline Correction factor & Reference value & Variability in inputs & Variability in outputs \\
\hline $\begin{array}{l}\text { Acceleration and } \\
\text { deceleration }\end{array}$ & $\begin{array}{l}|x| \geq 100 \mathrm{~m} \text { (distance to the } \\
\text { nearest crossing with traffic } \\
\text { lights or roundabout) }\end{array}$ & $|x|=100$ to $50 \mathrm{~m}$ & $\begin{array}{l}e_{\text {CAT2 }}=0.0 \% \text { to } 215.3 \% \\
e_{\text {CAT3 }}=0.0 \% \text { to } 202.8 \% \\
e_{\text {CAT4a }}=0.0 \% \text { to } 42.1 \% \\
e_{\text {CAT4b }}=0.0 \% \text { to } 42.1 \%\end{array}$ \\
\hline Road gradient & $\begin{array}{l}s=0 \% \text { (average slope along } \\
\text { the road segment) }\end{array}$ & $s=-1$ to $1 \%$ & $\begin{array}{l}e_{\text {CAT2 }}=0.0 \% \text { to } 16.3 \% \\
e_{\text {CAT3 }}=0.0 \% \text { to } 13.6 \% \\
e_{C A T 4 a}=0.0 \% \\
e_{C A T 4 b}=0.0 \%\end{array}$ \\
\hline Air temperature & $\begin{array}{l}T=20{ }^{\circ} \mathrm{C} \text { (yearly average air } \\
\text { temperature) }\end{array}$ & $T=15$ to $25^{\circ} \mathrm{C}$ & $\begin{array}{l}e_{\text {CAT2 }}=-6.9 \% \text { to } 7.4 \% \\
e_{\text {CAT3 }}=-6.8 \% \text { to } 7.2 \% \\
e_{\text {CAT4a }}=-8.1 \% \text { to } 8.8 \% \\
e_{\text {CAT4b }}=-8.1 \% \text { to } 8.8 \%\end{array}$ \\
\hline Studded tyres & $\begin{array}{l}p_{s}=0 \% \text { (yearly average } \\
\text { proportion of light vehicles } \\
\text { equipped with studded } \\
\text { tyres) }\end{array}$ & $\begin{array}{l}p_{s}=0 \text { to } 10 \% \text { ( } 30 \% \text { of light } \\
\text { vehicles equipped with } \\
\text { studded tyres from } \\
\text { December } 1 \text { st to March 31st) }\end{array}$ & $\begin{array}{l}e_{C A T 2}=0.0 \% \text { to }-9.7 \% \\
e_{C A T 3}=0.0 \% \text { to }-9.7 \% \\
e_{C A T 4 a}=0.0 \% \text { to }-9.7 \% \\
e_{C A T 4 b}=0.0 \% \text { to }-9.7 \%\end{array}$ \\
\hline
\end{tabular}

\subsection{Weighting factors for different times of the day}

The total noise costs per day and kilometre of road can be allocated to individual vehicles of different classes by using the weighting factors for different vehicle classes presented in Section 3.2. The daily noise costs per vehicle-kilometre thus obtained for each vehicle class can then be converted to noise costs per vehicle-kilometre by vehicle class and time of the day. To this end, weighting factors for different times of the day must be applied to account for differences in impacts of noise emissions between times of the day. Each weighting factor describes the relationship between the costs per vehicle-kilometre for a given time of the day and the daily costs per vehicle-kilometre (i.e. the costs for the day-evening-night period). Thus, the weighting factor for a vehicle class $i$ and a time period $T\left(f_{T, C A T i}\right)$ can be expressed as follows:

$$
f_{T, C A T i}=\frac{N C V_{T, C A T i}}{N C V_{\text {den, } C A T i}}
$$

Based on this relationship and using the equations presented in Section 3.1, the ratios between the weighting factors for different times of the day are expressed as follows:

$$
\begin{gathered}
\frac{f_{\text {night }, C A T i}}{f_{\text {day }, C A T i}}=\frac{N C V_{\text {night }, C A T i}}{N C V_{\text {day }, C A T i}}=\frac{10^{\frac{10}{10}} \cdot W_{\text {night }, C A T i} \cdot Q_{\text {day }, C A T i}}{W_{\text {day }, C A T i} \cdot Q_{\text {night }, C A T i}}=\frac{10^{\frac{10}{10}} \cdot v_{\text {day }, C A T i}}{v_{\text {night }, C A T i}} \\
\frac{f_{\text {evening }, C A T i}}{f_{\text {day }, C A T i}}=\frac{N C V_{\text {evening }, C A T i}}{N C V_{\text {day }, C A T i}}=\frac{10^{\frac{5}{10}} \cdot W_{\text {evening }, C A T i} \cdot Q_{\text {day }, C A T i}}{W_{\text {day,CATi }} \cdot Q_{\text {evening }, C A T i}}=\frac{10^{\frac{5}{10}} \cdot v_{\text {day }, C A T i}}{v_{\text {evening,CATi }}}
\end{gathered}
$$

Hence, it can be observed that ratios between the weighting factors for different times of the day depend on the average speed of the vehicles for each time period. As mentioned above, the average speed can be assumed to be the same for all time periods, thus resulting in constant ratios between the weighting factors for the same vehicle class, as expressed below:

$$
\begin{gathered}
f_{\text {night }, \text { CATi }}=10^{\frac{10}{10}} \cdot f_{\text {day }, \text { CATi }} \\
f_{\text {evening, CATi }}=10^{\frac{5}{10}} \cdot f_{\text {day,CATi }}
\end{gathered}
$$


The constants in Eq. (26) and Eq. (27) arise from the formula that defines the noise indicator $L_{\text {den }}$ (see Eq. (4)), which was devised to take into account the impact of time of the day. This indicator uses a weighted noise measure that increases evening noise by $5 \mathrm{dBA}$ and night noise by $10 \mathrm{dBA}$. These penalties for different times of the day, when expressed in terms of sound power (see Eq. (8)), lead to the aforementioned constants.

It can also be demonstrated that weighting factors for different times of the day are the same for all vehicle classes, as follows:

$$
\frac{f_{T, C A T i}}{f_{T, C A T r e f}}=\frac{N C V_{T, C A T i}}{N C V_{T, C A T r e f}} \cdot \frac{N C V_{\text {den,CATref }}}{N C V_{\text {den,CATi }}}=e_{C A T i} \cdot \frac{1}{e_{C A T i}}=1
$$

Moreover, in order to cover the total noise costs, the following equation must be satisfied:

$$
\sum_{i} A D T_{C A T i} \cdot N C V_{\text {den, } C A T i}=\sum_{i} \sum_{T} A D T_{T, C A T i} \cdot N C V_{T, C A T i}
$$

where $A D T_{C A T i}$ is the average daily traffic for the vehicle class $i$ during the day-evening-night period (in veh/day) and $A D T_{T, C A T i}$ is the average daily traffic for the vehicle class $i$ during the time period $T$ (in veh/day). Eq. (29) can be developed to obtain an additional relationship between the weighting factors for different times of the day, as shown below:

$$
\sum_{i} e_{C A T i} \cdot A D T_{C A T i}=\sum_{i} \sum_{T} A D T_{T, C A T i} \cdot e_{C A T i} \cdot f_{T}
$$

The weighting factors for different times of the day can be derived by combining Eq. (30) with Eq. (26) and Eq. (27). The weighting factors thus obtained are expressed as follows:

$$
\begin{gathered}
f_{\text {day }}=\frac{\sum_{i} e_{C A T i} \cdot\left(12 \cdot Q_{\text {day }, C A T i}+4 \cdot Q_{\text {evening }, C A T i}+8 \cdot Q_{\text {night }, C A T i}\right)}{\sum_{i} e_{C A T i} \cdot\left(12 \cdot Q_{\text {day }, C A T i}+4 \cdot 10^{\frac{5}{10}} \cdot Q_{\text {evening }, C A T i}+8 \cdot 10^{\frac{10}{10}} \cdot Q_{\text {night }, C A T i}\right)} \\
f_{\text {evening }}=\frac{\sum_{i} e_{C A T i} \cdot\left(12 \cdot Q_{\text {day }, C A T i}+4 \cdot Q_{\text {evening }, C A T i}+8 \cdot Q_{\text {night }, C A T i}\right)}{\sum_{i} e_{C A T i} \cdot\left(12 \cdot 10^{-\frac{5}{10}} \cdot Q_{\text {day }, C A T i}+4 \cdot Q_{\text {evening }, C A T i}+8 \cdot 10^{\frac{5}{10}} \cdot Q_{\text {night }, C A T i}\right)} \\
f_{\text {night }}=\frac{\sum_{i} e_{C A T i} \cdot\left(12 \cdot Q_{\text {day }, C A T i}+4 \cdot Q_{\text {evening,CATi }}+8 \cdot Q_{\text {night }, C A T i}\right)}{\sum_{i} e_{C A T i} \cdot\left(12 \cdot 10^{-\frac{10}{10}} \cdot Q_{\text {day }, C A T i}+4 \cdot 10^{-\frac{5}{10}} \cdot Q_{\text {evening }, C A T i}+8 \cdot Q_{\text {night }, C A T i}\right)}
\end{gathered}
$$

\section{Case study}

A case study is presented here in order to illustrate the application of the improved weighting factors to calculate the external costs of road traffic noise. The calculation method used in the case study is more complete than the method of the Eurovignette Directive (European Union, 2011) because it allows calculating the noise costs of various vehicle classes (passenger cars and HGVs) for three time periods (day, evening and night). The average noise costs per vehicle-kilometre by vehicle class and time of the day were thus calculated for three different Spanish motorways (Fig. 3). Data from strategic noise maps for these roads for the year 2006 were used as inputs for the calculations. The strategic noise maps were obtained from the Spanish Information System on Noise Pollution (Spanish Ministry of Agriculture, Food and Environment, 2007). Traffic and noise exposure data used for the calculations are shown in Table 4 and Table 5. 


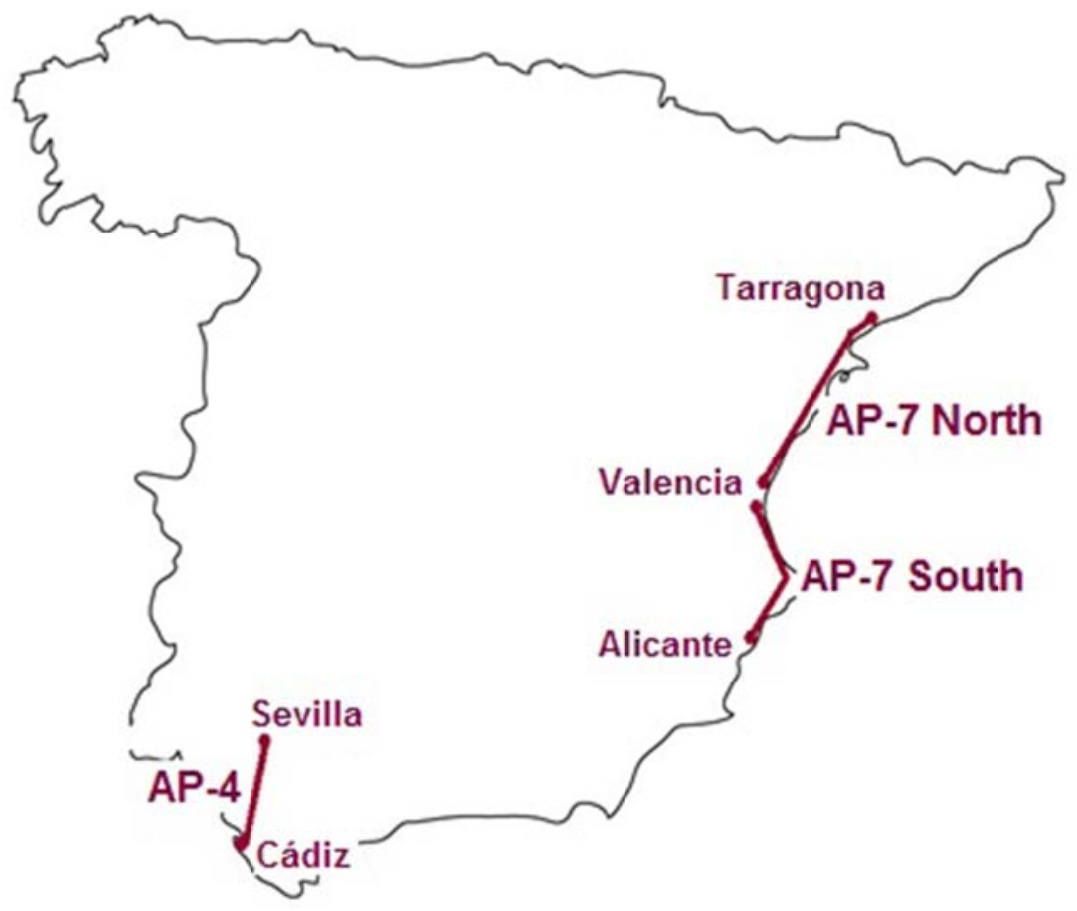

Fig. 3. View of the roads under study.

Table 4

Traffic flows and speeds by vehicle class and time of the day (Source: Spanish Ministry of Agriculture, Food and Environment, 2007).

\begin{tabular}{|c|c|c|c|c|c|c|}
\hline \multirow[t]{2}{*}{ Road name } & \multirow[t]{2}{*}{ Length $(\mathrm{km})$} & \multirow[t]{2}{*}{ Time of the day } & \multicolumn{2}{|c|}{ Light vehicles (CAT1) } & \multicolumn{2}{|c|}{ Heavy vehicles (CAT3) } \\
\hline & & & Flow (veh/h) & Speed $(\mathrm{km} / \mathrm{h})$ & Flow (veh/h) & Speed $(\mathrm{km} / \mathrm{h})$ \\
\hline \multirow[t]{3}{*}{ AP-7 North } & 221.5 & Day & 1079 & 120 & 362 & 100 \\
\hline & & Evening & 799 & 120 & 477 & 100 \\
\hline & & Night & 179 & 120 & 156 & 100 \\
\hline \multirow[t]{3}{*}{ AP-7 South } & 147.6 & Day & 1295 & 120 & 434 & 100 \\
\hline & & Evening & 959 & 120 & 572 & 100 \\
\hline & & Night & 150 & 120 & 131 & 100 \\
\hline \multirow[t]{3}{*}{ AP-4 } & 93.4 & Day & 1266 & 120 & 157 & 100 \\
\hline & & Evening & 1203 & 120 & 134 & 100 \\
\hline & & Night & 159 & 120 & 68 & 100 \\
\hline
\end{tabular}

Table 5

Number of persons exposed to noise per kilometre of road (Source: Spanish Ministry of Agriculture, Food and Environment, 2007).

\begin{tabular}{llllll}
\hline Road name & \multicolumn{5}{l}{ Noise levels $L_{\text {den }}$ by 5 dBA intervals } \\
\cline { 2 - 6 } & $55-60$ & $60-65$ & $65-70$ & $70-75$ & $>75$ \\
\hline AP-7 North & 90.29 & 26.19 & 4.06 & 0.45 & 0.00 \\
AP-7 South & 226.96 & 54.88 & 10.16 & 1.36 & 0.00 \\
AP-4 & 61.03 & 13.92 & 2.14 & 0.00 & 0.00 \\
\hline
\end{tabular}

In addition to traffic and noise exposure data, the calculation method requires the following inputs: noise costs per person exposed to road traffic noise, weighting factors for different vehicle classes and weighting factors for different times of the day. The noise costs for Spain per day per person exposed were based on the 
HEATCO project (Bickel et al., 2006). The HEATCO values were adjusted to year 2006 for purchasing power parity (i.e. the values were expressed as $€_{2006}$ PPP) and were bundled in $5 \mathrm{dBA}$ intervals as shown in Table 6.

Table 6

Noise costs for Spain per year per person exposed to road traffic noise.

\begin{tabular}{ll}
\hline Noise levels $L_{\text {den }}$ by 5 dBA intervals & $\begin{array}{l}\text { Noise costs per year per person exposed } \\
\left(€_{2006} \text { PPP/person/year }\right)\end{array}$ \\
\hline $55-60$ & 58 \\
$60-65$ & 99 \\
$65-70$ & 141 \\
$70-75$ & 226 \\
$75-80$ & 303 \\
\hline
\end{tabular}

The weighting factors for light vehicles (CAT1) are always 1 because they are taken as the reference vehicle class. The weighting factors for heavy vehicles (CAT3) were calculated according to the vehicle speeds by using Eq. (22). The weighting factors for different times of the day were calculated according to the traffic flows by vehicle class and time of the day by using Eq. (31) to Eq. (33). The weighting factors both for different vehicle classes and for different times of the day are shown in Table 7.

Table 7

Weighting factors for different vehicle classes and times of the day for the roads under study.

\begin{tabular}{lllllll}
\hline \multirow{2}{*}{ Road name } & \multicolumn{2}{l}{ Weighting factors for different vehicle classes: $e_{C A T i}$} & & \multicolumn{4}{l}{ Weighting factors for different times of the day: $f_{T}$} \\
\cline { 2 - 3 } & Light vehicles (CAT1) & Heavy vehicles (CAT3) & & Day & Evening & Night \\
\hline AP-7 North & 1.00 & 2.02 & 2.02 & 0.39 & 1.24 & 3.92 \\
AP-7 South & 1.00 & 2.02 & 0.44 & 1.39 & 4.40 \\
AP-4 & 1.00 & & &
\end{tabular}

Noise exposure data were combined with noise costs per day per person exposed to calculate the total noise costs. Data on traffic flows by vehicle class and weighting factors for different vehicle classes were used to translate the total noise costs into the average noise costs per vehicle-kilometre by vehicle class. Weighting factors for different times of the day were applied to determine the average noise costs per vehicle-kilometre by vehicle class and time of the day. The total and average noise costs for each of the roads studied are shown in Table 8.

Table 8

Total and average costs of traffic noise for the roads under study.

\begin{tabular}{|c|c|c|c|c|c|c|c|}
\hline \multirow[t]{3}{*}{ Road name } & \multirow{3}{*}{$\begin{array}{l}\text { Total noise costs: } N C_{d e n} \\
\left(€_{2006} \mathrm{PPP} / \mathrm{km} / \text { day }\right)\end{array}$} & \multicolumn{6}{|c|}{ Average noise costs: $N C V_{T, C A T i}\left(€ c t_{2006}\right.$ PPP/vehicle-km) } \\
\hline & & \multicolumn{3}{|c|}{ Light vehicles (CAT1) } & \multicolumn{3}{|c|}{ Heavy vehicles (CAT3) } \\
\hline & & Day & Evening & Night & Day & Evening & Night \\
\hline AP-7 North & 23.30 & 0.028 & 0.088 & 0.279 & 0.056 & 0.178 & 0.563 \\
\hline AP-7 South & 55.72 & 0.065 & 0.205 & 0.648 & 0.131 & 0.414 & 1.309 \\
\hline AP-4 & 14.30 & 0.023 & 0.074 & 0.233 & 0.047 & 0.149 & 0.471 \\
\hline
\end{tabular}

\section{Discussion}

The weighting factors developed here allow the calculation of the external costs of road traffic noise within the framework of the Eurovignette Directive (European Union, 2011). These factors have a high level of differentiation in order to provide reliable noise costs of various vehicle classes for different times of the day. The benefits of these factors can be exposed by comparing them with those found in previous work. 
Differentiated weighting factors for a wide range of vehicle classes are available from CE Delft (van Essen et al., 2004), but these only distinguish two types of road: urban roads, where the speed is $50 \mathrm{~km} / \mathrm{h}$; and other roads, where the speed is $80 \mathrm{~km} / \mathrm{h}$ or higher (see Table 1). A single set of weighting factors is given by CE Delft for various vehicle classes travelling on urban roads. However, the factors for urban roads may be highly variable because they are subject to large variations in regional parameters (e.g. acceleration and deceleration) that influence them (see Table 3). Although urban roads are outside the scope of this study, since the Eurovignette Directive does not apply to them, it should be noted that improved factors for urban roads could be obtained by taking regional variations into account (provided that their values are known) with a suitable traffic noise emission model. Another single set of weighting factors is given by CE Delft for various vehicle classes travelling on other roads, which include both suburban and interurban roads to which the Eurovignette Directive applies. The same factors are thus applied to suburban and interurban roads, or more general to all roads classified as other roads, i.e. roads where the speed is $80 \mathrm{~km} / \mathrm{h}$ or higher. However, weighting factors for different vehicle classes vary depending on the speed of the vehicles. To take this variability into account, the factors developed herein are differentiated according to the speeds of the vehicles (see Eq. (22)). Moreover, the weighting factors for different vehicle classes given by CE Delft are specific for the Netherlands, while factors for the average European road vehicles would be more convenient. The factors developed here are based on the traffic noise emission model CNOSSOS-EU (Kephalopoulos et al., 2012), which provides noise emission values for the average European road vehicles. These factors can therefore be regarded as European average values, thus being more suitable to be generalized to any road in Europe. With respect to differentiation according to time period, weighting factors for different times of the day are not available from previous work. Some studies have estimated marginal noise costs for different times of the day based on specific case studies (Bickel et al., 2003; Nash and partners, 2003; Müller-Wenk and Hofstetter, 2003; Schreyer et al., 2004). However, the results of case studies are hardly transferable to any European road because marginal noise costs are sensitive to existing traffic flows. To overcome this limitation, the weighting factors for different times of the day developed herein are expressed as a function of the traffic flows by vehicle class and time of the day (see Eq. (31) to Eq. (33)). These factors distinguish three time periods, namely day, evening and night periods, while the Eurovignette Directive and the aforementioned studies only distinguish day and night periods. The inclusion of the evening period is preferable since noise effects during evening are different from noise effects during day or night. The factors provided here are therefore more reliable than those found in earlier studies, as they are highly differentiated to better account for the influence of key cost drivers, namely vehicle class, speed and time of the day. In addition to key cost drivers, there are some regional parameters that may have significant effects on weighting factors (see Table 3). The CNOSSOS-EU model includes correction factors to take into account the variations in regional parameters. Site-specific weighting factors could thus be obtained, although data required for the calculations are scarce, especially when a top-down approach is applied.

The lack of differentiation according to vehicle speed in the weighting factors provided in earlier studies can lead to a misjudgement of the noise costs attributable to vehicles of different classes. If the weighting factors for different vehicle classes given by CE Delft (van Essen et al., 2004) had been used in the case study instead the improved factors, the error involved would have varied from -37.36 to $-24.27 \%$ for the cost of one passenger car and from 30.24 to $57.46 \%$ for the cost of one HGV, depending on the road assessed. Therefore, the charges to be borne by HGVs would have been highly overestimated in this case, which would have not been consistent with the polluter pays principle that should guide the charging for the use of road infrastructure. It should also be noted that a bottom-up approach was applied in the case study instead of a top-down approach as stated by the Eurovignette Directive (European Union, 2011). As a result, significant differences were observed between the average noise costs for the different roads assessed (see Table 8); the costs for AP-7 South were more than double the costs for AP-7 North and almost triple the costs for AP-4. These differences could have been even greater if the vehicle speeds had been different for each road. If a top-down approach had been applied in the case study, the average noise costs would have been the same for all roads assessed, which would have also been inconsistent with the polluter pays principle. The bottom-up approach is better from a theoretical point of view, since it takes into account local factors that directly influence the size of noise costs (e.g. traffic conditions and population density close to the road). Despite this, the bottom-up approach has not been widely applied 
because it has usually required more data and time. However, the lack of data has been resolved by the publication of the strategic noise maps required by the Environmental Noise Directive (European Commission, 2002). EU Member States are obliged to periodically provide traffic data and maps on noise exposure for all their major roads. A bottom-up approach could thus be applied to calculate the noise costs for each major road based on data from strategic noise maps and applying the weighting factors developed here. In fact, the calculation of external cost of road traffic noise could become part of the action plans that the Environmental Noise Directive requires EU Member States to adopt.

\section{Conclusions}

The Eurovignette Directive (European Union, 2011) provides a method to calculate the external costs of road traffic noise. This method requires the use of weighting factors for different vehicle classes to account for differences in noise costs between vehicle classes. The use of weighting factors for different times of the day is also required to distinguish between noise costs for day and night periods. However, the Eurovignette Directive does not provide specific values or guidelines to calculate these weighting factors, and research findings are scarce and do not seem to be clearly substantiated. For this reason, improved weighting factors both for different vehicle classes and for different times of the day have been developed herein. These factors are more reliable than those found in previous studies, as they are highly differentiated to better account for the influence of key cost drivers, namely vehicle class, speed and time of the day. Other second-order cost drivers that may influence weighting factors could be taken into account with a suitable traffic noise emission model. Unlike weighting factors given in earlier studies, the improved factors can be regarded as suitable to be generalized to any road in Europe. The method of the Eurovignette Directive has been extended to vehicle classes other than HGVs by applying the weighting factors provided here. Likewise, it has been extended to consider not only the day and night periods but also the evening period.

\section{References}

Bickel, P., Friedrich, R., Burgess, A., Fagiani, P., Hunt, A., De Jong, G., Laird, J., Lieb, C., Lindberg, G., Mackie, P., Navrud, S., Odgaard, T., Ricci, A., Shires, J., Tavasszy, L., 2006. Developing Harmonised European Approaches for Transport Costing and Project Assessment (HEATCO) - Deliverable D5: Proposal for Harmonised Guidelines. Institute of Energy Economics and the Rational Use of Energy (IER), University of Stuttgart, Stuttgart.

Bickel, P., Schmid, S., Tervonen, J., Hämekoski, K., Otterström, T., Anton, P., Enei, R., Leone, G., van Donselaar, P., Carmigchelt, H., 2003. Unification of accounts and marginal costs for transport efficiency (UNITE) - Deliverable 11: Environmental marginal cost case studies. Institute of Energy Economics and the Rational Use of Energy (IER), University of Stuttgart, Stuttgart.

European Commission, 1995. Towards fair and efficient pricing in transport - Policy options for internalising the external costs of transports in the European Union, Green Paper, COM(1995) 691 final. European Commission, Brussels.

European Commission, 1998. Fair Payment for Infrastructure Use: A phased approach to a common transport infrastructure charging framework in the EU, White Paper, $\operatorname{COM(1998)~} 466$ final. European Commission, Brussels.

European Commission, 1999. Directive 1999/62/EC of the European Parliament and of the Council of 17 June 1999 on the charging of heavy goods vehicles for the use of certain infrastructures. Official Journal of the European Communities, EU.

European Commission, 2001. European transport policy 2010: time to decide, White Paper, COM(2001) 370 final. European Commission, Brussels.

European Commission, 2002. Directive 2002/49/EC of the European Parliament and of the Council of 25 June 2002 relating to the assessment and management of environmental noise. Official Journal of the European Communities, EU.

European Commission, 2006a. Communication from the Commission to the Council and the European Parliament - Keep Europe moving - Sustainable mobility for our continent - Mid-term review of the European Commission's 2001 Transport White Paper, $\operatorname{COM(2006)} 314$ final. European Commission, Brussels. 
European Commission, 2006b. Directive 2006/38/EC of the European Parliament and of the Council of 17 May 2006 amending Directive 1999/62/EC on the charging of heavy goods vehicles for the use of certain infrastructures. Official Journal of the European Union, EU.

European Commission, 2008. Communication from the Commission to the European Parliament and the Council - Greening Transport, $\operatorname{COM(2008)} 433$ final. European Commission, Brussels.

European Commission, 2011. Roadmap to a Single European Transport Area - Towards a competitive and resource efficient transport system, White Paper, $\operatorname{COM(2011)} 144$ final. European Commission, Brussels.

European Conference of Ministers of Transport, 1998. Efficient Transport for Europe - Policies for Internalisation of External Costs. ECMT Publications, Paris.

European Union, 2011. Directive 2011/76/EU of the European Parliament and of the Council of 27 September 2011 amending Directive 1999/62/EC on the charging of heavy goods vehicles for the use of certain infrastructures. Official Journal of the European Union, EU.

Kephalopoulos, S., Paviotti, M., Anfosso-Lédée, F., 2012. Common Noise Assessment Methods in Europe (CNOSSOS-EU). To be used by the EU Member States for strategic noise mapping following adoption as specified in the Environmental Noise Directive 2002/49/EC. Publications Office of the European Union, Luxembourg.

Maibach, M., Schreyer, C., Sutter, D., van Essen, H.P., Boon, B.H., Smokers, R., Schroten, A., Doll, C., Pawlowska, B., Bak, M., 2008. Handbook on estimation of external costs in the transport sector. Produced within the study Internalisation Measures and Policies for All external Cost of Transport (IMPACT). CE Delft, Delft.

Müller-Wenk, R., Hofstetter, P., 2003. Monetisation of the health impact due to traffic noise. Environmental documentation no. 166. Swiss Agency for the Environment, Forests and Landscape (SAEFL), Bern.

Nash, C., with contributions from partners, 2003. Unification of accounts and marginal costs for transport efficiency (UNITE) - Final Report for publication. Institute for Transport Studies (ITS), University of Leeds, Leeds.

OECD/INFRAS/Herry, 2003. External costs of transport in Central and Eastern Europe, for the OECD Environment Directorate, Working Party on National Environmental Policy, Working Group on Transport. INFRAS/Herry Consulting, Zurich/Vienna.

Peeters, B., van Blokland, G., 2007. Improved Methods for the Assessment of the Generic Impact of Noise in the Environment (IMAGINE) - The noise emission model for European road traffic. Deliverable 11 of the IMAGINE Project. TNO, Vught.

Schreyer, C., Schneider, C., Maibach, M., Rothengatter, W., Doll, C., Schmedding, D., 2004. External costs of transport Update study. INFRAS/IWW, Zurich/Karlsruhe.

Spanish Ministry of Agriculture, Food and Environment, 2007. Mapas Estratégicos de Ruido de las Autopistas de la Red del Estado: Autopista AP-7 (Tarragona - Valencia), Autopista AP-7 Sur (Valencia - Alicante), Autopista AP-4 (Sevilla - Cádiz). Documento Resumen. <http://sicaweb.cedex.es> (September 2012).

van Essen, H.P., Boon, B.H., den Boer, L.C., Faber, J., van den Boss, M.A., Vervoort, K.T.H., Roche, C., 2004. Marginal costs of infrastructure use - towards a simplified approach. CE Delft, Delft.

VROM, 2002. Reken-en meetvoorschrift wegverkeerslawaai 2002. VROM, The Hague. 